\title{
Essential Trace Element Status of Pregnant Women with Pregnancy Complication History in Benin City, Nigeria
}

\section{*OTEBHI, GE; OSADOLOR, HB}

\author{
Department of Medical Laboratory Science, School of Basic Medical Sciences, University of Benin, Benin City, Nigeria. \\ *Corresponding Author Email: godwinoteb@gmail.com
}

\begin{abstract}
Essential trace elements are catalytic substances needed by the human body in small amount. The objective of this study was to determine the serum levels of selected essential trace elements (copper, zinc, iron and selenium) in pregnant women with history of pregnancy complications in Benin City, Nigeria using appropriate standard methods for blood. Sample collection and analysed by EAAS. Result showed that pregnant women with complications history had blood mean (mean \pm SEM) levels of Copper $(\mu \mathrm{g} / \mathrm{l})=107.47 \pm 0.18$, Zinc $(\mu \mathrm{g} / \mathrm{l})=86.19 \pm 0.41$, Iron $(\mu \mathrm{g} / \mathrm{l})=$ $108.50 \pm 0.18$ and Selenium $(\mu \mathrm{g} / \mathrm{l})=42.13 \pm 0.39$; while those without complications history had blood mean levels of Copper $=125.65 \pm 1.60$, Zinc $=91.91 \pm 0.84$, Iron=112.26 \pm 0.33 and Selenium $=46.47 \pm 0.32$. The non-pregnant women who never had complications in their previous pregnancies had blood mean levels of Copper $=129.91 \pm 1.49$, Zinc $=108.08 \pm$ 0.52 , Iron $=136.58 \pm 0.80$ and Selenium $=51.32 \pm 0.10$. Pregnant women with complications history recorded very high significant reduction $(\mathrm{P}<0.001)$ in the essential trace elements mean values compared to pregnant and non-pregnant women without complications. Reduction in the essential trace elements has negative impact on the development of pregnancy complications among pregnant women in Benin City, Nigeria.
\end{abstract}

\section{DOI: https://dx.doi.org/10.4314/jasem.v23i10.10}

Copyright: Copyright (C 2019 Otebhi and Osadolor. This is an open access article distributed under the Creative Commons Attribution License (CCL), which permits unrestricted use, distribution, and reproduction in any medium, provided the original work is properly cited.

Dates: Received: 22 August 2019; Revised: 22 October 2019; 28 October 2019

Keywords: Essential, Elements, Pregnancy, Complications.

The physiological importance of essential trace elements prior to and during pregnancy is well established in order to optimize the health and wellbeing of both mother and child (Allen, 2005). Pregnancy is a period of increased metabolic demands and it involves changes in a woman's physiology and the requirements of a growing fetus. Most essential trace elements functions as essential co-factors and as an antioxidant. Oxidative stress is generated during normal placenta development, however, when the supply of essential trace elements is limited, exaggerated oxidative stress within both the placenta and maternal circulation occur and this may lead to adverse pregnancy outcomes (Hiten et al 2011, Mohsen, 2014)). Numerous researchers have investigated the role of trace elements in pregnancy especially the effects of both maternal under and over nutrition on the long term health of the offspring. A number of hypotheses have been suggested to explain the contribution of maternal nutrition during the fetal and embryonic period and the programming of the cardiovascular and metabolic system of the offspring (Solomons, 2009, Mohammed et al 2010). Maternal nutritional deficiencies typically occur as a result of low dietary intakes of essential nutrients. Although the negative effects of diets low in energy in pregnancy outcomes are well documented, the effects of diets low in one or more essential trace elements have not been adequately studies especially in the South South region of Nigeria coupled with the well documented fact that wide variations in most essential trace elements occur in human probably due to geographical locations, soil content, intake in diet and bioavailability (Nwagha et al 2011). In addition to the contribution of macronutrition to successful pregnancy, more recent studies have begun to focus on the role of essential micronutrients or trace elements, so called because they are an absolute requirement and are required in only small amounts daily (Ajayi et al, 2012, Sukhsate 2015). The aim of this present study was to determine the serum levels of selected essential trace elements Copper, Zinc, Iron and Selenium in pregnant women with history of pregnancy complications in Benin City, Nigeria.

\section{MATERIALS AND METHODS}

Study Area: The study was done in Benin City, the capital and largest city of Edo State in South - South Nigeria, between January and October 2015. Benin City, the leading home of arts and culture in Nigeria is situated on a branch of the Benin river within the rain forest zone of the South South region of Nigeria. The city is estimated to have $1,125,058$ people (Nigeria population update 2015). The site of the study was Central Hospital Benin, a referral hospital situated at the city centre.

Study Population: A total of 135 apparently healthy women comprising of 45 pregnant women with one or more history of previous pregnancy complications (such as maternal bleeding, complications of abortion, severe anaemia, placenta previa, gestational diabetes, 
birth defects etc) and 45 pregnant women without any history of previous pregnancy complications (all within the 1 st and into the 2 nd trimesters) and 45 nonpregnant women without history of pregnancy complication were recruited for this study after obtaining verbal informed consent from the subjects and ethical clearance from the Edo State Ministry of Health and Central Hospital authority. The pregnant women were aged between $21-35$ years and within the gestational age of $0-20$ weeks recruited from the Antenatal Clinic of Central Hospital, Benin City. All the women were matched for age and social economic status. Women who were 36 years and above, those with symptoms of diseases such as fever, and increased blood pressure, those already on nutritional supplements and those with multiple pregnancies were excluded from this study. Some demographic and basic health indices were obtained from them through direct questioning / measurement and the use of ANC cards and case notes of pregnant subjects. All the subjects were subjected to the same instruments and method of measurement.

Reagents and solution used: Analytical reagent grade TCA and glycerin were from Sigma Chemical USA. Stock and working solutions of Copper, Zinc, Iron and Selenium were prepared using deionized water. Blank solutions were prepared in the same way. Cleaning of the equipment was done by using distilled water.

Apparatus: All the glass ware and apparatus used were cleaned using distilled water and soaked in $20 \%$ TCA

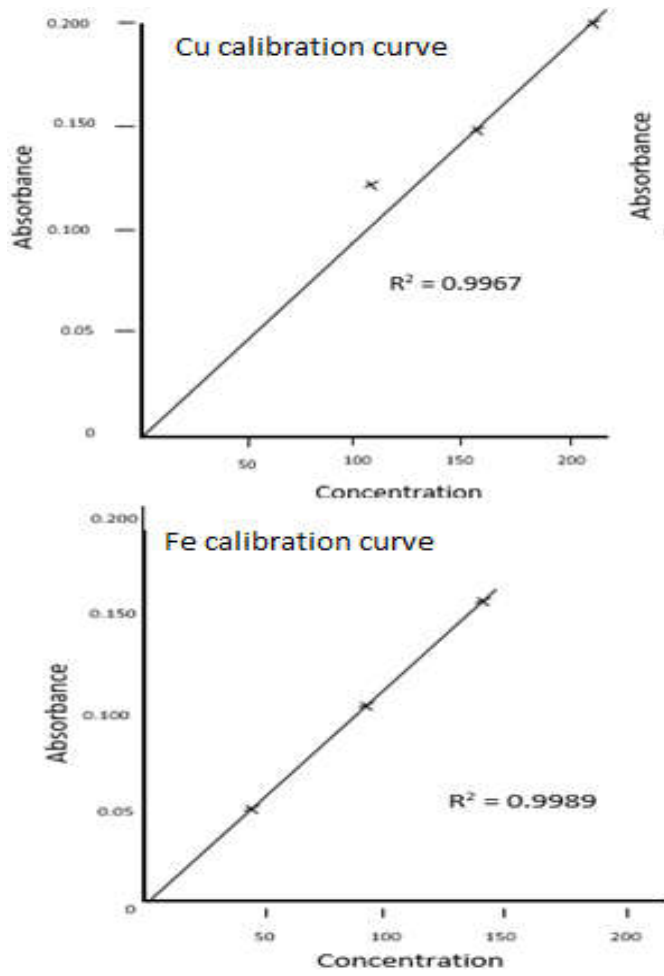

before use. All the working solutions were prepared using de-ionized water.

Specification of AAS: Model Peckin Elmer Analysts 800; Wavelength $=200-900 \mathrm{~nm}$; Light Source = Hollow cathode lamp; Frequency $=100-400 \mathrm{H}_{\mathrm{z}}$; Photometer type=Single beam; Data processing system=Absorbance concentration; Read out mode $=$ Digital display

Preservation of serum samples: The serum samples were stored in deep frozen state at $-80^{\circ} \mathrm{C}$ and kept without repeated freeze-thaw cycles prior to analysis

Digestion of sample: Serum samples for Copper, Zinc and Selenium analysis were treated directly after diluting with de-ionized water except those for Iron analysis that were treated with 20\% TCA 1:2 and then aspirate the supernatant fluid from a different container.

Preparation of samples and standards for analysis: Samples were prepared by diluting with de-ionized water before analysis. Different concentration of standard solutions were prepared from stock standard. Standard and blank solutions were treated with 5\% glycerin to enhance viscosity before use. There were correlation between standard and signals. The calibration curve for all the selected trace elements were straight line and their correlation coefficients $\left(\mathrm{R}^{2}\right)$ ranged from $0.9967-\mathrm{Cu}, 0.9969-\mathrm{Se}, 0.9979-\mathrm{Fe}$ to $0.9989-\mathrm{Zn}$ as shown in figure 1 .

Fig 1. Calibration curves for $\mathrm{Cu}, \mathrm{Se}, \mathrm{Fe}$ and $\mathrm{Zn}$ 
Statistical Analysis: Values were recorded as mean and standard error of mean with graphical presentations. Comparison of mean was by one-way analysis of variance (ANOVA) followed by student $t$ test at 0.05 level of significance.

\section{RESULTS AND DISCUSSION}

most developing countries of the world. Due to the increased metabolic demands occasioned by the growing fetus, pregnant women are known to be associated particularly with high level of vulnerability to nutritional deficiencies. Most researchers have shown that diets low in essential micro-nutrients can pose a significant reproductive risk. Gestational events usually generate oxidative stress. Some essential trace elements or micro-nutrients are known to function as antioxidants or co-factors. Insufficient supply of these essential trace elements will further worsen the oxidative stress within the maternal circulation thereby leading to severe pregnancy outcomes. The role of essential trace elements with regards to the development of pregnancy complications have been well reported in most countries and in the South East and South West regions of Nigeria (Nwagha et al., 2011, Ajayi et al.,2012). In this study, we observed highly significant decrease in the serum levels of copper, zinc, iron and selenium of pregnant women with history of pregnancy complications compared with pregnant women and non-pregnant women that are without history of pregnancy complications. These findings are partly in agreement with the findings of Ajayi et al (2012) in the South-Western region of Nigeria who also reported low plasma levels of copper and zinc but with significant increase in plasma selenium levels of pregnant women with history of recurrent spontaneous abortion and with the work of Nwagha et al (2011), in the South-Eastern Nigeria who reported a rise in the serum copper levels, but with decrease in the serum selenium levels of healthy pregnant women. These differences may be attributed to geographical, cultural and nutritional differences. Copper, an essential trace element, is an important constituent of some vital enzymes that functions as antioxidant and oxidoreductase. It is important for reproduction and its required for normal metabolic processes. Deficiency of copper have been reported to be associated with lipid peroxidation resulting in high oxidative damage which can adversely lead to some pregnancy complications such as embroyonic death and structural abnormality. Different studies have reported high serum copper level during normal pregnancy (McArdle, 1995, Nwagha, 2011).

Table 1: Some demographic and basic health indices of pregnant and non-pregnant women with status of complications enrolled in the

\begin{tabular}{|c|c|c|c|c|}
\hline Variables & $\begin{array}{l}\text { PWWHC } \\
n=45\end{array}$ & $\begin{array}{l}\text { PWWTHC } \\
n=45\end{array}$ & $\begin{array}{l}\text { NPWWTHC } \\
n=45\end{array}$ & P - values \\
\hline \$Mean age (Years) & $27.40 \pm 5.10$ & $28.24 \pm 3.34$ & $27.84 \pm 3.37$ & \multirow{11}{*}{$P=0.05$} \\
\hline $\begin{array}{l}\text { Mean gestational } \\
\text { age (weeks) }\end{array}$ & $13.98 \pm 2.82$ & $14.56 \pm 2.65$ & Nil & \\
\hline State of Origin & $\begin{array}{l}\text { Edo, } n=14(31.1 \%) \\
\text { Delta, } n=11(24.4 \%)\end{array}$ & $\begin{array}{l}n=16(35.5 \%) \\
n=9(20.0 \%)\end{array}$ & $\begin{array}{l}n=13(28.5 \%) \\
n=12(26.7 \%)\end{array}$ & \\
\hline & $\begin{array}{l}\text { Baxelsa, } n=9(20.0 \%) \\
\text { A bra-Ihom } n=7(15.6 \%)\end{array}$ & $\begin{array}{l}n=8(20.0 \%) \\
n=8(17.8 \%)\end{array}$ & $\begin{array}{l}\mathrm{n}=9(20.0 \%) \\
\mathrm{n}=8(17.8 \%)\end{array}$ & \\
\hline & Cross river, $n=14(8.9 \%)$ & $n=5(11.1 \%)$ & $n=3(6.6 \%)$ & \\
\hline \multirow{6}{*}{$\begin{array}{l}\text { *Socio-economic } \\
\text { status }\end{array}$} & $\begin{array}{l}\text { Teachers (primary), } n=13(28.9 \%) \\
\text { Teachers (secondary), } n=6(13.3 \%)\end{array}$ & $\begin{array}{l}\mathrm{n}=10(22.2 \%) \\
\mathrm{n}=8(17.8 \%)\end{array}$ & $\begin{array}{l}n=9(20.0 \%) \\
n=7(15.6 \%)\end{array}$ & \\
\hline & $\begin{array}{l}\text { Traders, n } 3(6.7 \%) \\
\text { lat }\end{array}$ & $\mathrm{n}=4(8.9 \%)$ & $\mathrm{n}=5(11.1 \%)$ & \\
\hline & Hairdreagers $n=8(17.8 \%)$ & $\mathrm{n}=5(11.1 \%)$ & $\mathrm{n}=6(13.3 \%)$ & \\
\hline & Office clerk, $n=5(11.1 \%)$ & $\mathrm{n}=8(17.8 \%)$ & $n=6(13.1 \%)$ & \\
\hline & Cashiers, $n=6(13.3 \%)$ & $\mathrm{n}=5(11.1 \%)$ & $\mathrm{n}=7(15.6 \%)$ & \\
\hline & Receptionists, $n=4(8.9 \%)$ & $\mathrm{n}=5(11.1 \%)$ & $\mathrm{n}=5(11.1 \%)$ & \\
\hline \multirow{13}{*}{$\begin{array}{l}\text { Mean Blood } \\
\text { pressure: } \\
\text { Systolic Diastolic } \\
\text { Health status: } \\
\text { Number of } \\
\text { Previous pregnancy } \\
\text { (NPP) } \\
\text { Status of Previous } \\
\text { pregnancy } \\
\text { complications }\end{array}$} & $117.01+16.11$ & $116.94 \quad 16.10$ & $116.43,16.09$ & \multirow{13}{*}{$P=0.05$} \\
\hline & $\overline{77.42} \pm \overline{4.04}$ & $\overline{77.23} \pm \overline{4.01}$ & $\overline{76.96} \pm \overline{3.93}$ & \\
\hline & Apparently healthy & Apparently healthy & Apparently healthy & \\
\hline & $1.87 \pm 0.65$ & $1.69 \pm 0.66$ & $1.69 \pm 0.63$ & \\
\hline & Matemal bleeding $n=5(11.1 \%)$ & Nil & $\mathrm{Nil}$ & \\
\hline & Spontameous abortion, $n=7(15.6 \%)$ & Nil & Nil & \\
\hline & Severe Anzemia, $n=7(15.6 \%)$ & Nil & Nil & \\
\hline & Hypertension, $n=3(6.6 \%)$ & Nil & $\begin{array}{l}\text { Nil } \\
\text { Nil }\end{array}$ & \\
\hline & Premature labour, $n=5(11.1 \%)$ & Nil & $\begin{array}{l}\text { Nil } \\
\text { Nil }\end{array}$ & \\
\hline & Preeclampsia, $n=3(6.6 \%)$ & Nil & Nil & \\
\hline & Gestational DM, n $=5(11.1 \%)$ & Nil & Nil & \\
\hline & Placenta pre & Nil & Nil & \\
\hline & & Nil & Nil & \\
\hline
\end{tabular}

Note: $P W W H C=$ Pregnant women with history of pregnancy complications; $P W W T H C=$ Pregnant women without history of pregnancy complications; NPWWTCH = Non-pregnant women without history of pregnancy complications; * Participant were matched for Age and socio-economic status 
Table 2. Absorbance of $\mathrm{Cu}, \mathrm{Zn}, \mathrm{Fe}$ and Se. Standard calibration of trace elements

\begin{tabular}{cll}
\hline Trace elements & Concentrate $(\boldsymbol{\mu g} / \mathbf{l})$ & Absorbance \\
\hline & 100 & 0.1050 \\
& 150 & 0.1510 \\
$\mathrm{Zn}$ & 200 & 0.2010 \\
& 150 & 0.1510 \\
& 100 & 0.1710 \\
$\mathrm{Fe}$ & 150 & 0.1530 \\
& 50 & 0.0490 \\
& 100 & 0.1020 \\
$\mathrm{Se}$ & 150 & 0.1500 \\
& 20 & 0.0210 \\
& 40 & 0.0402 \\
& 60 & 0.0615 \\
\hline
\end{tabular}

Table 3: Serum mean levels of $\mathrm{Cu}, \mathrm{Zn}, \mathrm{Fe}$ and $\mathrm{Se}$ in pregnant and non-pregnant women with status of complications in Benin City.

\begin{tabular}{llllll}
\hline Parameters & $\begin{array}{l}\text { Pregnant Women } \\
\text { with complications }\end{array}$ & $\begin{array}{l}\text { Pregnant Women } \\
\text { without complications }\end{array}$ & $\begin{array}{l}\text { Non-pregnant women } \\
\text { without complications }\end{array}$ & $\begin{array}{l}\text { P- } \\
\text { values }\end{array}$ & Significant \\
\hline $\mathrm{Cu}(\mu \mathrm{g} / \mathrm{l})$ & $107.47 \pm 061$ & $125.65 \pm 60$ & $129.91 \pm 1.49$ & $\mathrm{P}<0.001$ & Highly significant \\
$\mathrm{Zn}(\mu \mathrm{g} / \mathrm{l})$ & $86.19 \pm 0.41$ & $91.91 \pm 0.84$ & $108.08 \pm 0.52$ & $\mathrm{P}<0.001$ & Highly significant \\
$\mathrm{Fe}(\mu \mathrm{g} / \mathrm{l})$ & $108.30 \pm 0.48$ & $112.26 \pm 0.33$ & $136.58 \pm 0.80$ & $\mathrm{P}<0.001$ & Highly significant \\
$\mathrm{Se}(\mu \mathrm{g} / \mathrm{l})$ & $42.13 \pm 0.39$ & $46.47 \pm 0.32$ & $51.32 \pm 0.10$ & $\mathrm{P}<0.001$ & Highly significant \\
\hline
\end{tabular}

The changes are steady and consistent from the first trimester to third trimester with a statistically significant difference observed only between the third trimester and the controls (Non-pregnant women). However in this study, we recorded a significant decrease in the serum copper level for pregnant women with complications compared with pregnant and nonpregnant women without complications. This trend was seen in pregnant women without complications compared with non-pregnant women that are also without complications. The significant decrease might be as a result of increase fetal needs for copper and hemodilution associated with pregnancy and also, the fact that all the pregnant women enrolled in this study were within first and second trimester and have not commenced nutritional supplements as confirmed by the subjects recruited into this study. This however may require further study.

The ability of zinc to retard oxidative stress have been recognized for many years. Zinc is an essential trace element that is vital for metabolism. It is a constituent of a number of metalloenzymes, nucleic acid synthase and antioxidant function. Zinc deficiency has been associated with preeclampsia, prolong labour and fetal growth restriction (Mackenzie et al 2012, Summers 2012). Serum zinc levels in this study were found to be significantly reduced for pregnant women with history of pregnancy complication compared with pregnant women and non-pregnant women who were without history of pregnancy complication.

A similar decrease was recorded for pregnant women without history of pregnancy complication when their serum mean zinc levels were compared with that of non-pregnant women without history of pregnancy complications. Figures $2-5$ show the comparison of the selected trace elements in pregnant and nonpregnant women with complication status.

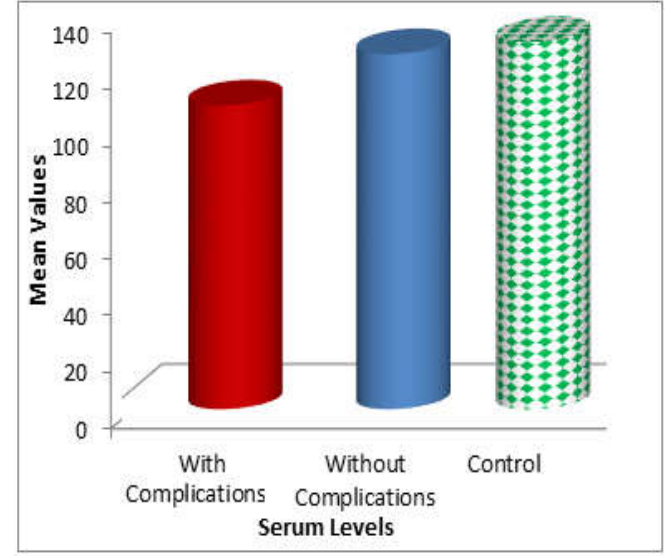

Figure 2: Bar chart showing the comparison of Copper in pregnant and non-pregnant women (control) with complication status. High significant reduction of mean Copper values $(\mathrm{p}<0.001)$ in pregnant women with complications was obtained compared to pregnant and non-pregnant women without complication.

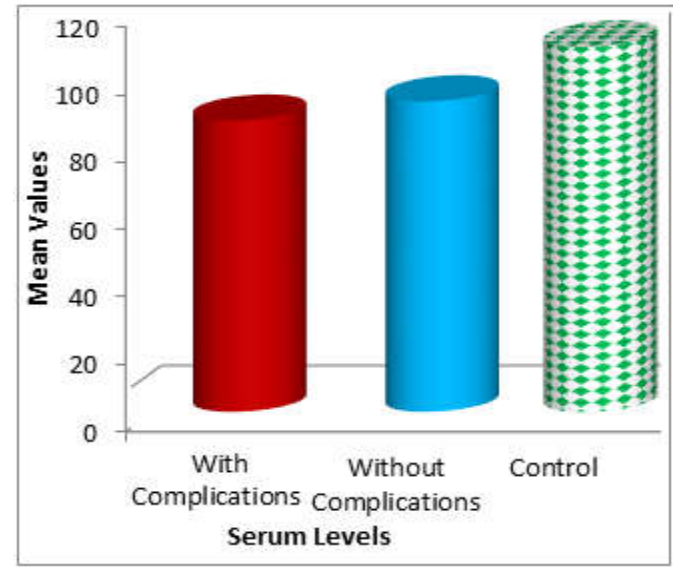

Figure 3: Bar chart showing the comparison of Zinc in pregnant and non-pregnant women (control) with complication status High significant reduction of mean Zinc values $(\mathrm{p}<0.001)$ in pregnant women with complications was obtained compared to pregnant and non-pregnant women without complication. 


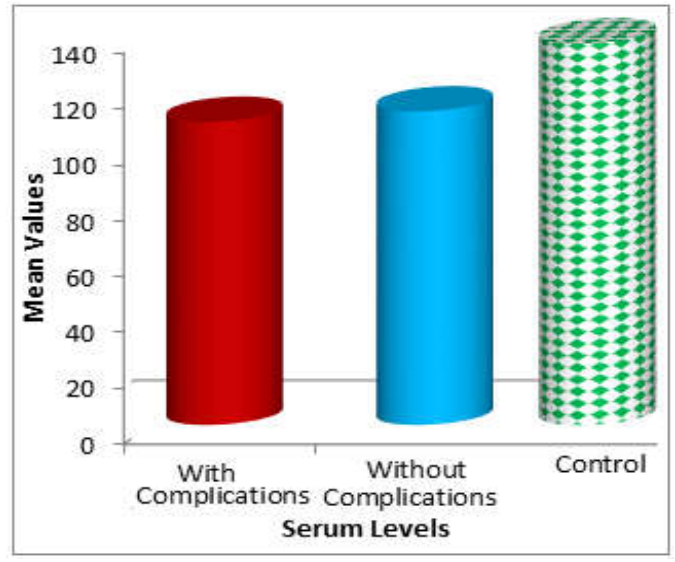

Figure 4: Bar chart showing the comparison of Iron in pregnant and non-pregnant women (control) with complication status. High significant reduction of mean Iron values $(\mathrm{p}<0.001)$ in pregnant women with complications was obtained compared to pregnant and non-pregnant women without complication.

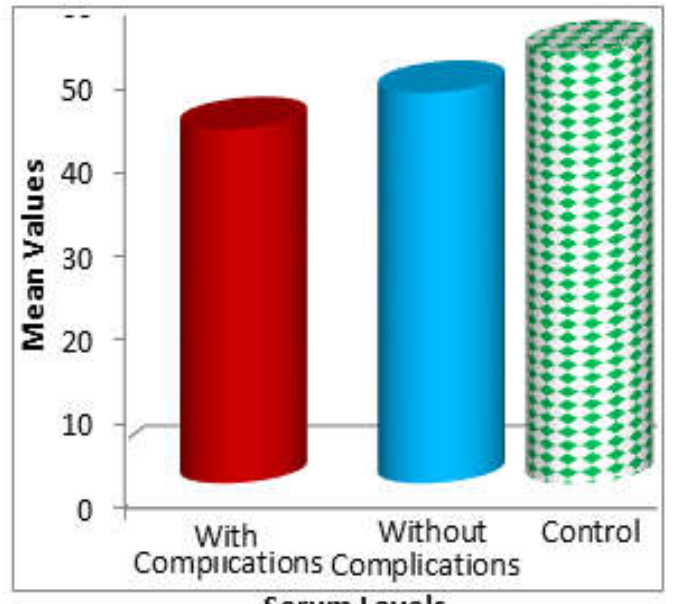
Serum Levels

Figure 5: Bar chart showing the comparison of Selenium in pregnant and non-pregnant women (control) with complication status. High significant reduction of mean Selenium values $(\mathrm{p}<0.001)$ in pregnant women with complications was obtained compared to pregnant and non-pregnant women without complication.

Zinc has been described to be catalytic, structural and regulatory in functions. In its catalytic function, zinc is an important component of the catalytic site of hundreds of metallloenzymes. In its structural function, zinc coordinates with certain protein domains thereby facilitating protein folding and producing structures such as zinc fingers. In its regulatory function, zinc is involved in the regulation of nucleoproteins and the activities of various inflammatory cells e.g. the expression of metallothionein for intracellular zinc compartmentalization and antioxidant functions (Chaffee et al 2002). Studies in animals have shown that zinc deficiency in expectant mothers can distort both the sequency and efficiency of the birth process. Zinc deficiency in humans is known to result from dietary intake, inadequate absorption, increased loss or increased utilization as in pregnancy. This can negatively affect the mother or fetus eg. Prolong labour, bleeding and placenta previa etc. (Chaffee et $a l, 2002)$. These effects may be brought about by the defective functioning of estrogen through the estrogen receptor that has a zinc finger protein. Iron deficiency is well established to be a contributor to abnormal prenatal development and pregnancy outcome. Several studies have shown that iron stores at conception are strong predictor of maternal iron status and risk of anaemia in later pregnancy. Mounting evidences revealed that maternal iron deficiency in pregnancy reduces fetal iron stores perhaps well into the first year of life (Allen, 2000). Selenium is an essential antioxidant trace element that is invaluable in the protection of tissues against oxidative stress. It is a component of selenoproteins such as the antioxidant enzyme glutathione perozidase which protect human tissue against oxidative damage. It is also very useful for healthy growth and for reproduction (Patrick, 2004). Wide variations in selenium is known to occur in human probably due to geographical location, soil content, intake in diet and its bioavailability. Selenium requirement is increased in pregnancy as a result of transport to the growing fetus. Some studies outside South South Nigeria and in other countries have shown the relationship of selenium deficiency with some pregnancy complications such as spontaneous abortion (Nwagha et al 2011). In this study we observed a significantly reduced serum selenium levels for pregnant women with history of pregnancy complications compared with the controls. Comparing pregnant women without history of pregnancy complications with the controls (non-pregnant women without history of pregnancy complications), we also observed a significant reduction in the serum selenium levels for pregnant women. These findings are however contrary to the findings in the South West region of Nigeria where significant increases were observed in pregnant women with history of recurrent spontaneous abortion (Ajayi et al 2012), but agrees with the findings in the South-eastern part of Nigeria where a significant decrease were also observed in healthy pregnant women (Nwagha et al 2011). These differences might be partly due to geographical location, and intake from diets. The significant depression recorded in the essential trace elements mean values for pregnant women with history of pregnancy complications compared to the controls, might be associated with the development of pregnancy complications among pregnant women in Benin City, South-South, Nigeria.

Conclusion: Our study showed a generalized reduction of the selected essential element or micronutrients $\mathrm{Cu}, \mathrm{Zn}, \mathrm{Fe}$ and Se among pregnant women in Benin City. Pregnancy creates a special metabolic demand for high quality nutrients. We therefore advocate that much effort should be put in place by the Government and other stakeholders in the health sector to ensure adequate and regular supply of these nutritional 
supplements to reproductive-age-mothers in our clinics and hospitals in order to advert possible negative pregnancy outcomes that may be associated with reduced blood trace elements levels.

\section{REFERENCES}

AJAYI OO, CHARLES-DAVIS MA, ARINOLA OG. (2012). Progesterone, selected heavy metals and micronutrients in pregnant Nigeria women with history of recurrent spontaneous abortion. Af. J. H. Sc., 12(2): $153-158$

ALLEN LH. (2005). Multiple micronutrients in pregnancy and lactation: an overview. Am. J. Clinic. Nut. 81 (5) 1206 - 1212.

ALLEN LH. (2000). Anaemia and Iron Deficiency: Effects on Pregnancy Outcomes. Am. J. Clinic. Nut. 71(5) 1280 - 1284.

CHAFFEE BN, KING SC. (2002). Effect of zinc supplementation in pregnancy and infant outcomes a systematic review. Paediatr. and Prenat. Epidemiol. 26(1): 118-137.

HITEN CD, CHRISTOPHER WG, FIONA BP, LUCILLA P. (2011). Selenium in reproductive health. Am. J. Ob. Gynae. 206(1): 21-30

MACKENZIE CG, ZAGO MP, KEEN CL, OTEIZA PI. (2002). Low intracellular zinc impairs the translocation of activated NF-Kappa B. to the nuclei in human neuroblastoma. J. Biol. Chem 277: $34610-34617$.

MCARDLE HJ. (1995). The Metabolism of Copper during pregnancy - a review food chem. 54: 77- 84.
MOHAMMED, J, YAKOS Y, PERVEZ $\mathrm{K}$ and ZULFIGOR AB (2010). Material mineral and vitamin supplementation in pregnancy. Expt. Rev. Ob. Gynae. 5; 241-256.

MOHSEN V. (2014). Effects of lead and other metals on pregnancy outcomes. Junte. Med. Jnr. 21(5); 65-171.

NWAGHA UI, OGBODO SO, NWOGU-IKOJO EE, IBEGBU DM, EJEZIE FE, NWAGHA TU, DIM CC. (2011). Copper and selenium status of healthy pregnant women in Enugu south eastern Nigeria. Nig. J. Clin. Prt. 14(4): $408-412$.

Nigeria Population update (2015).

OLMEDO P, PLA A, HERNADEZ AF, LOPEZGUANID O, RODINGO L, GIL F. (2010). Electrothermal Atomization - Atomic Absorption Spectrometry (ET-AAS), Anal. Clin. Acts 659: 60 $-67$.

PATRICK L. 2004. Selenium biochemistry and Canar. A Review of the Literature. Altern. Med. Rev. 9: $239-258$.

SOLOMONS NW. 2009. Developmental Origins of Health and Disease: Concepts, Caveats, and Consequences for Public Health Nutrition. Nutri. Rev. 67(1): $12-16$.

SUKHSATE B (2015). Importance of trace elements in the human body. Healthy Eating, 492 - 4.

SUMMERS A (2012). Emergency management of hyperemesis gravidarum. Emerg. Nurs, 20 (4). 24 $-28$. 